\title{
An ethical dilemma: A case of student training, intermittent service and impact on service delivery
}

\author{
P Govender, BOT, MOT, CAMAG \\ Discipline of Occupational Therapy, College of Health Sciences, University of KwaZulu-Natal, Durban, South Africa
}

Corresponding author: P Govender (née Naidoo) (naidoopg@ukzn.ac.za)

One of the fundamental precepts in the training of students in a clinical discipline involves appropriate placement and supervision in order for learning outcomes to be achieved. As an academic/clinical educator, one is at times faced with dilemmas in student placement that challenge one's personal and professional ethics. This paper highlights one case example that describes student training and the impact on service delivery.

Afr J Health Professions Educ 2015;7(1):8-9. DOI:10.7196/AJHPE.405

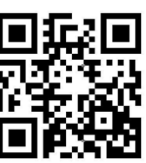

Training within clinical disciplines is often challenging In this paper, the author seeks to critically reflect on and evaluate the principle of justice in student training using vignettes to describe dilemmas that surfaced during the clinical placement of students.

Fieldwork placement is mandatory in most clinical training programmes. In an attempt to facilitate learning through integration of theory and praxis, one is faced with the challenge of creating these 'real life' situations for students in which opportunities are provided for application of knowledge and skills learnt in the lecture room. It is postulated that certain factors are essential for determining a successful learning experience, viz. a well-planned placement, with sufficient time for the clinical educator to meet individual students regularly throughout the placement and for sufficient clients to be available for each student.

Given the constraints within institutions in terms of human resources, availability to accommodate students, client turnovers, etc., certain training programmes may lean towards repeatedly using a particular facility to provide the required fieldwork experience. An example below is described to highlight some of the challenges in such a situation.

\section{A case example}

While transformation within health science faculties is progressing in South Africa (SA), teaching has shifted from central hospitals to secondary and district hospitals, community health centres and rural areas. ${ }^{[1]}$ In this example, a chronic-care facility has been re-used as a venue for training of occupational therapy students (in a 4-year undergraduate degree programme). The facility is a specialised hospital with 175 beds, providing services to chronically ill clients in need of nursing care. Approximately 10 - 15 students are placed in each rotation, which may very well be viewed as 'exploitation' of the facility for training purposes. After review of events that occurred in this facility, the author was bound to pose the question: At what cost to the clients are students provided with these necessary periods of knowledge and skill development?

Table 1 lists vignettes of three patients' experiences. The examples are quoted from anecdotal evidence, i.e. informal discussions and observations within this facility.

\section{Reflections and discussion}

As an academic/clinical educator and congruently as an observer within this context, I noted the following as concerns:
- The issue and concern over sustainability of services, which raises the question of whether it is ethical to provide a standard of care or intervention that differs from the normal routine services provided in such settings. The contravention of common-law duty of continuation of intervention is raised, as seen in Thabo's case.

- Issues around identification of clients for rehabilitation intervention and perceived incidental or consequential exclusion of others, as in Mary's case.

- Clients receiving intermittent services appeared to be disadvantaged by this prevailing system, as described in Alan's case. These sporadic services raise the question of whether placement of students is disadvantageous to an under-resourced facility.

The ethical dilemmas above are commonly found in the provision of health services. Distributive justice ${ }^{[2]}$ (how to dispense or allocate resources); nonmaleficence $^{[3]}$ (the obligation to avoid doing harm directly or indirectly); and paternalism ${ }^{[2]}$ (making decisions for others in what is considered to be their best interests) are issues that are often raised. Consequently a number of occupational injustices ${ }^{[4]}$ were identified, viz. occupational deprivation ${ }^{[4]}$ (when persons cannot engage in occupations that are necessary and meaningful to them because of factors outside their control) as in Mary's case; occupational alienation ${ }^{[4]}$ (when people experience a prolonged disconnectedness, emptiness, and/or sense of meaninglessness) as in Alan's case, and occupational imbalance ${ }^{[4]}$ (when some people are over-occupied and others are under-occupied).

Distributive justice: Severe limitation of resource personnel and need for services

When ethically arguing for equal access to healthcare for all, the principle of justice and its derivative, distributive justice, is essential. Under section 27 of the SA Constitution, ${ }^{[5]}$ access to healthcare is a recognised right, and in order to achieve success in the provision of health services, there is a need for human rights and ethicolegal principles to be adhered to as monitors of this process. The onus is on the state and therefore staff employed by the state to ensure that steps are taken to realise these rights. However, the provision of the rights depends on whether resources are available.

Reid and Cakwe ${ }^{[1]}$ highlighted human resource challenges faced by health sciences faculties in SA. Lack of resources has terminated blocks which had 


\title{
Table 1. Vignettes
}

\begin{abstract}
Vignette 1
Thabo* is a 34-year-old African male, admitted to the facility 3 years ago from a Respite Unit. Diagnosed with stage three, symptomatic retroviral disease, with a $\mathrm{CD} 4$ count of 180 . He is currently on highly active antiretroviral therapy. He suffered a bilateral cerebrovascular accident 5 months ago and has comorbidities of hepatitis B and encephalomyelitis. Thabo was referred to a third-year student with a focus on therapeutic intervention (rehabilitation). Rehabilitation was clientcentred towards achieving goals aimed at improving Thabo's quality of life at this stage of care. He responded well to interventions, making gains in his overall motivation, endurance and ability to execute personal management tasks with assistive devices and adaptations. Later that year, he was referred to a secondyear student with a focus on assessment. This process was used as a reassessment of the gains Thabo had made in therapy; however, there were no sustained therapeutic interventions. In the period between these two rotations of students Thabo did not receive any rehabilitation (approximately 3 - 4 months).

\section{Vignette 2}

Mary ${ }^{*}$ is a 68-year-old Afrikaans-speaking lady who has been residing in the facility for 15 years because of the degenerative nature of her condition (multiple sclerosis). She has symptoms related to loss of sensitivity, general muscular weakness, spasms, incoordination and chronic pain. She is bowel and bladder incontinent and has an unstable mood. She is in a ward with 15 other clients, 10 of whom were engaged in rehabilitation with students. Mary would often verbalise to the students the need to be part of the programme; however, she had not been identified as requiring intervention by the resident rehabilitation therapists. She would often be seen lingering outside therapy areas, and at times in emotional outbursts, swearing profanities at her fellow in-patients who received interventions, indicative of the apparent preference for some clients over others.

\section{Vignette 3}

Alan, ${ }^{*}$ a 48 -year-old Indian male, was diagnosed with a severe traumatic brain injury and C4 complete spinal injury following a hijacking and assault incident. He was admitted to the unit from a rehabilitation setting. He had undergone 8 months of rehabilitation prior to admission. He was allocated to a student in the first rotation in the year and benefitted from individual and group rehabilitation. The students left by mid-year and a new group of students returned 2 months later. During this time, Alan received minimal intervention. When approached to consent to treatment by another student, Alan refused, indicating his refusal was due to non-sustainability of services.
\end{abstract}

${ }^{*}$ Names have been changed to maintain confidentiality.

previously involved students in community-based projects. This burden has at times been reduced through university and government collaboration.

Notwithstanding this, should students then be placed in under-resourced settings given that the general public suffers from the consequence of any decision pertaining to resource distribution and therefore access to healthcare?[2]

\section{Autonomy, beneficence and non-maleficence ${ }^{[4]}$}

The notion of autonomy accepts that a mentally/legally competent client has the capacity to understand, reflect, reason and make an informed decision. In the context of rehabilitation services, this would imply that a mentally/ legally competent individual would be able to make an independent decision on whether or not to receive services. Therapists, on the other hand, are obliged, by virtue of their registration with the Health Professions Council of South Africa, to allocate services primarily on the basis of need. The reality in this setting is that clients are screened, based on their individual needs, and the issue of the client's willingness to receive these services is raised (autonomy), despite informed consent.

It could be argued that provision of services, albeit intermittently, benefits the client. In many rural sites where there are few therapists, students provide a service that would otherwise not have existed. ${ }^{[2]}$ In this case the placement of students could be seen as an act of beneficence. ${ }^{[4]}$ Students prepare detailed handovers with recommendations for continued intervention when they leave. Alan's experience however demonstrates that clients could feel a sense of abandonment, loneliness and experience negative emotions. This may be a violation of the principle of non-maleficence. This 'harm', though not envisaged, needs to be considered at both the referral and handover stages as the service provided is not acting in the best interest of the client (beneficence). According to the Patient's Rights Charter to which all practitioners ascribe, no client may be abandoned by a healthcare practitioner, who initially took on the responsibility for the client's health. ${ }^{[1]}$ Clients are therefore assured of continuity of care.

\section{Conclusion}

Training of students within natural clinical environments other than lecture rooms appears to succeed only when specific supports and accommodations are provided to both students and the recipients of the service. While an opportunity for optimal learning, these situations often raise issues of ethical and moral responsibilities that tug at one's own professional intentions. In the effort to reach outcomes as required by an educational curriculum, the goal of ensuring optimal healthcare to clients remains a paramount professional ethical responsibility. This report was intended to highlight just a few ethical dilemmas that surfaced in one setting. The author remains challenged in ensuring that there is balance between what students can contribute, the demands teaching places on the system for support, and carefully managing ethical principles while ensuring sustainability of these educational initiatives.

Acknowledgement. The author would like to acknowledge Mrs N Motala for her insights into the bioethics and health law.

\section{References}

1. Reid SJ, Cakwe M. The contribution of South African curricula to prepare health professionals for working in rural or under-served areas in South Africa: A peer review evaluation. S Afr Med J 2011;101:34-38

2. Dhai A, McQuoid-Mason D. Bioethics, Human Rights and Health Law. Principles and Practice. Cape Town: Juta, 2011. 3. Gelling L. Ethical principles in healthcare research. Nursing Standard 1999;13(36):39-42.

4. Duncan M, Watson R. Transformation through occupation: Towards a prototype. In: Watson R, Swartz L, eds. Transformation Through Occupation. London: Whurr Publishers, 2004:301-318.

5. Constitution of the Republic of South Africa. Act 108 of 1996. Butterworth's Statutes of South Africa, February 2007. http://www.gov.za/sites/www.gov.za/files/images/a108-96.pdf (accessed 16 April 2015). 